\title{
Aplikasi Pemetaan Lokasi Nasabah FIFGROUP Kota Manado
}

\author{
Erlandy Aristianto, Arie S.M.Lumenta, Yaulie D.Y.Rindengan \\ TeknikInformatika UniversitasSamRatulangiManado, Indonesia. \\ aristiantoerlandy@gmail.com, lumenta@unsrat.ac.id,rindengan@unsrat.ac.id
}

Perusahaan pembiayaan (finance) adalah badan usaha yang melakukan kegiatan pembiayaan untuk pengadaan barang atau jasa (POJK No. 29/2014). Perkembangan perusahaan pembiayaan di wilayah perkotaan, khususnya di wilayah kota Manado mengalami kemajuan yang sangat pesat, dilihat dari banyaknya perusahaan pembiayaan yang membuka cabang di Manado. Penelitian ini bertujuan untuk membuat suatu aplikasi pemetaan lokasi nasabah FIFGROUP di Kota Manado berbasis android yang interaktif dan visualisasi yang menarik dalam pencarian peta dan sebagai informasi yang diinginkan oleh perusahaan sehingga mempermudah dan membantu dalam proses pendataan nasabah FIFGROUP. Android adalah sebuah sistem operasi untuk perangkat mobile berbasis linux yang mencakup sistem operasi, middleware dan aplikasi. Android menyediakan platform terbuka bagi para pengembang untuk menciptakan aplikasi mereka. Awalnya, Google Inc. membeli Android Inc. yang merupakan pendatang baru yang membuat piranti lunak untuk ponsel atau smartphone. Metode penelitian dalam pembuatan aplikasi pemetaan lokasi nasabah FIFGROUP kota manado ini menggunakan Rapid Application Development (RAD).

Kata Kunci: Android, FIFGROUP, Pemetaan, Rapid Application Development (RAD).

Finance company is a business entity that carries out financing activities for the procurement of goods or services (POJK No. 29/2014). The development of finance companies in urban areas, especially in the city of Manado, has progressed very rapidly. FIFGROUP currently only provides data in the form of print media so that sometimes collectors find it difficult to get the right address for customers. This study aims to create an application mapping location of FIFGROUP customers in the city of Manado based on Android which draws visualization in map searches and as information desired by the company so as to facilitate and assist in the FIFGROUP customer data collection process. Android is an operating system for Linux-based mobile devices that includes operating systems, middleware and applications. Android provides an open platform for developers to create their applications. The research method in making the customer location mapping application for FIFGROUP in Manado uses Rapid Application Development (RAD).

Keywords: Android, FIFGROUP, Mapping, Rapid Application Development (RAD).

\section{PENDAHULUAN}

Seiring perkembangan teknologi yang semakin pesat, kini segala sesuatu dituntut untuk lebih cepat dan mudah. Begitupun halnya dengan memperoleh informasi. Kita pasti menginginkan informasi yang kita butuhkan itu dapat diperoleh dengan mudah dan cepat. Dengan teknologi informasi yang berkembang saat ini, pengelolaan informasi dapat dilakukan secara lebih aktual dan optimal. Penggunaan teknologi informasi bertujuan untuk mencapai efisiensi dalam berbagai aspek pengelolaan informasi, yang ditunjukkan dengan kecepatan dan ketepatan waktu pemrosesan serta ketilitian dan keakuratan informasi. Dimana informasi tersebut dibutuhkan oleh berbagai pihak, seperti instansi pemerintah, pelaku bisnis, wisatawan, maupun masyarakat umum untuk dimanfaatkan sesuai keperluan masingmasing.

FIFGROUP saat ini merupakan salah satu sarana pengkreditan terbesar di Kota Manado. FIFGROUP adalah grup perusahaan yang bergerak di bidang pembiayaan konsumen, terutama untuk pembiayaan motor dan produk-produk elektronik.Banyaknya informasi terkadang menyulitkan seseorang untuk mencapai tempat tujuannya dan kecewa dengan hasil yang berbeda seperti yang di dengar melalui berita maupun mulut ke mulut. Dalam menentukan letak alamat para nasabah FIFGROUP yang akan di tempuh atau di datangi dengan menggunakan peta konvensional dan memilih jalur yang terpendek dari tempat asal ke tujuan. Namun hal ini sering kali tidak dapat membantu secara maksimal karena kebanyakan kita pasti harus menanyakan satu per satu warga di sekitar untuk memastikan alamat atau keberadaan nasabah tersebut dan itu bisa dibilang tidak efisien. Sistem informasi geografis merupakan sebuah sistem yang dapat membantu memudahkan para kolektor FIFGROUP untuk menggali informasi tempat para nasabah atau konsumen yang akan di kunjungi dan letaknya.

Untuk itu diperlukan suatu Aplikasi yang dapat

membantu dalam mempresentasikan data nasabah yang ada. Oleh karena itu berdasarkan latar belakang diatas penulis ingin membuat Aplikasi guna mendukung kinerja para kolektor di perusahaan dengan judul"A Aplikasi Pemetaan Lokasi Nasabah FIFGROUP Kota Manado “.

\section{A. Sistem Informasi}

Sistem informasi dalam suatu organisasi dapat dikatakan sebagai suatu sistem yang menyediakan informasi bagi semua tingkatan dalam organisasi tersebut kapan saja diperlukan. Sistem ini menyimpan, mengambil, mengubah, mengolah dan mengkomunikasikan informasi yang diterima dengan menggunakan sistem informasi atau peralatan sistem lainnya. Definisi sistem informasi dalam bukunya Abdul Kadir yang berjudul Pengenalan Sistem Informasi, yaitu: "sistem informasi adalah kerangka kerja yang mengkoordinasikan sumber daya 
(manusia), komputer) untuk mengubah masukan (input) menjadi keluaran (informasi), guna mencapai sasaran-sasaran perusahaan". Penjelasan diatas menerangkan bahwa sistem informasi dapat mempermudah perusahaan dalam mencapai sasaran yang telah ditargetkan dengan mengkoordinasikan manusia dan komputer. sebagai sumber daya untuk mengubah masukan menjadi pengeluaran yang diinginkan. Sistem informasi juga dapat memudahkan pekerjaan disuatu perusahaan-perusahaan.

Sistem informasi dikembangkan untuk tujuan yang berbedabeda, tergantung pada kebutuhan bisnis. Terdapat beberapa cara untuk mengelompokkan sistem informasi. Klasifikasi yang umum dipakai menurut (Kadir, 2003) antara lain didasarkan pada:

1) Level organisasi

2) Area fungsional

3) Dukungan yang diberikan, dan

4) Arsitektur sistem informasi

Berdasarkan ketiga pengklasifikasian tersebut sistem informasi dibagi lagi menjadi beberapa bagian, ini dimaksudkan agar jenis sistem informasi lebih jelas. Menurut level organisasi sistem informasi dibagi menjadi tiga jenis yaitu, sistem informasi departemen, sistem informasi perusahaan dan sistem informasi antar organisasi. Sistem informasi organisasi adalah sistem informasi yang hanya digunakan pada level organisasi saja, misalnya salah satu aplikasi digunakan untuk memantau pegawai. Jenis sistem informasi yang kedua adalah sistem informasi area fungsional, adalah sistem informasi yang ditujukan untuk memberikan informasi bagi kelompok orang yang berada pada bagian tertentu dalam perusa-haan. Sedangkan sistem informasi berdasarkan dukungan yaitu berdasarkan dukungan yang diberikan kepada pemakai, sistem informasi yang digunakan pada semua areal fungsional. Sistem informasi terkadang diklasifikasikan berdasarkan aktivitas pada level manajemen. Berdasarkan hal ini terdapat pengelompokan sebagai berikut: sistem informasi pengetahuan, sistem informasi operasional, sistem informasi manajerial dan sistem informasi strategis.

\section{B. Android}

Android adalah sebuah sistem operasi untuk perangkat mobile berbasis linux yang mencakup sistem operasi, middleware dan aplikasi. Android menyediakan platform terbuka bagi para pengembang untuk menciptakan aplikasi mereka. Awalnya, Google Inc. membeli Android Inc. yang merupakan pendatang baru yang membuat piranti lunak untuk ponsel atau smartphone. Kemudian untuk mengembangkan Android dibentuklah Open Handset Alliance (OHA), konsorium dari 34 perusahaan peranti keras, peranti lunak, dan telekomunikasi termasuk Google, HTC, Intel, Motorola, Qualcomm, TMobile dan Nvidia.

Pesatnya pertumbuhan Android karena Android itu sendiri adalah platform yang sangat lengkap baik itu sistem operasinya, Aplikasi dan Tool Pengembangan, Market aplikasi android serta dukungan yang sangat tinggi dari komunitas Open Source di dunia, sehingga android terus berkembang pesat baik dari segi teknologi maupun dari segi jumlah device yang ada di dunia).
Android dipuji sebagai "platform mobile pertama yang Lengkap, Terbuka, dan Bebas”. Lengkap (Complete Platform), dimana para desainer dapat melakukan pendekatan yang komprehensif ketika mereka sedang mengembangkan platform Android. Android merupakan sistem operasi yang aman dan banyak menyediakan tools dalam membangun software dan memungkinkan untuk peluang pengembangan aplikasi. Terbuka (Open Source Platform), adalah Platform Android disediakan melalui lisensi open source. Pengembang dapat dengan bebas untuk mengembangkan aplikasi. Free (Free Platform), dimana android adalah platform atau aplikasi yang bebas untuk develop. Tidak ada lisensi atau biaya royalti untuk dikembangkan pada platform android. Tidak ada biaya keanggotaan, dan biaya pengujian. Tidak ada kontrak yang diperlukan. Aplikasi android ini dapat didistribusikan dan diperdagangkan dalam bentuk apapun (Nazruddin, 2012). Android terbagi atas empat lapisan utama, yaitu:

1) Linux kernel, dilapisan ini berisikan device tingkatan rendah dari komponen perangkat keras pada android device.

2) Libraries, berisikan semua kode dan menyediakan fitur-fitur utama di android OS.

3) Android runtime berada dilapisan yang sama dengan libraries. Android runtime menyediakan sebuah kumpulan inti libraries yang dapat membuat para pengembang aplikasi android menggunakan java programming.

4) Application framework, membuka berbagai macam kemampuan OS android untuk pengembang aplikasi sehingga mereka dapat memakai semuanya diaplikasi yang dibuatnya.

5) Application, berada dilapisan paling atas dan digunakan untuk aplikasi yang berhubungan dengan android device, di mana aplikasi yang diunduh dan diinstall dari pasar android.

\section{FIF GROUP}

PT Federal International Finance (FIF) adalah perusahaan pembiayaan yang dimiliki sepenuhnya oleh Astra. Bisnis FIF awalnya difokuskan pada pembiayaan konvensional dan Syariah untuk mendukung penjualan ritel sepeda motor Honda. Selanjutnya telah dikembangkan produk pembiayaan sepeda motor bekas dan SPEKTRA sebagai kredit barang konsumsi umum, termasuk elektronik dan peralatan rumah tangga. "Salah satu prioritas utama dalam fokus kerja FIF adalah intensifikasi jaringan distribusi dengan mengutamakan sinergi dan hubungan antar fungsi dengan mitra kerja, baik dalam lingkungan jaringan bisnis Astra, Honda Sales Operation, dealer otomotif dan lainnya" untuk pengembangan operasional produk, di antaranya produk joint financing. Inovasi produk, seperti SPEKTRA card, bertujuan untuk ekspansi dan diversifikasi basis pelanggan.

Untuk menunjang seluruh upaya tersebut, pelayan yang maksimal bagi nasabah juga menjadi prioritas utama dalam penanganan keluhan nasabah, yang dilakukan berdasarkan fokus di tingkat cabang atau departemen terkait sehingga respon dan penyelesaian dapat ditindaklanjuti dengan cepat dan tepat, umumnya dalam jangka waktu 2 x 24 jam.

\section{Finance}

Finance adalah mempelajari bagaimana individu, bisni, dan organisasi meningkatkan, mengalokasi, dan menggunakan 
sumber daya moneter sejalan dengan waktu dan juga menghitung risiko dalam menjalankan proyek mereka. Istilah keuangan(finance) dapar berarti :

1) Ilmu keuangan, dan asset lainnya

2) Manajemen asset tersebut

3) Menghitung, dan mengatur risiko proyek

Finance mempunyai kemiripan dengan Ekonomi. Dalam ekonomi kita memperlajari mengalokasi sumber daya yang terbatas sedangkan finance kita mempelajari bagaimana sumber daya yang terbatas itu dialokasikan.

\section{E. GPS}

GPS atau Global Positioning System, merupakan sebuah alat atau sistem yang dapat digunakan untuk menginformasikan penggunanya berada (secara global) di permukaan bumi yang berbasiskan satelit. Data dikirim dari satelit berupa sinyal radio dengan data digital. Dimanapun posisi saat ini, maka GPS bisa membantu menunjukan arah, selama masih terlihat langit. Layanan GPS ini tersedia gratis, bahkan tidak perlu mengeluarkan biaya apapun kecuali membeli GPS recierver-nya.

Awalnya GPS hanya digunakan hanya untuk kepentingan militer, tapi pada tahun 1980-an dapat digunakan untuk kepentingan sipil. GPS dapat digunakan dimanapun juga dalam 24 jam. Posisi unit GPS akan ditentukan berdasarkan titiktitik koordinat derajat lintang dan bujur.

\section{F. Google Maps}

Google Maps adalah layanan pemetaan desktop yang web yang dikembangkan oleh Google. Menawarkan citra satelit, peta jalan, $360^{\circ}$ panorama jalan-jalan (Street View), kondisi lalu lintas real-time (Google Traffic), dan perencanaan rute untuk bepergian dengan berjalan kaki, mobil, sepeda (dalam versi beta), atau angkutan umum.Google Maps dimulai sebagai program desktop $\mathrm{C}++$ dirancang oleh Lars dan Jens Rasmussen Eilstrup pada Where 2 Technologies. Layanan ini menggunakan Javascript, XML, dan Ajax. Google Maps menawarkan API yang memungkinkan peta untuk dimasukkan pada situs web pihak ketiga, dan menawarkan locator untuk bisnis perkotaan dan organisasi lainnya di berbagai negara di seluruh dunia. Google Map Maker memungkinkan pengguna dalauntuk bersama-sama mengembangkan dan memperbarui pemetaan layanan di seluruh dunia.

Tampilan satelit Google Maps 'adalah "top-down". Sebagian besar citra resolusi tinggi dari kota adalah foto udara yang diambil dari pesawat yang terbang pada 800 sampai 1.500 kaki (240-460 m), sementara sebagian besar citra lainnya adalah dari satelit. Sebagian besar citra satelit yang tersedia adalah tidak lebih dari tiga berusia tahun dan diperbarui secara teratur Google Maps menggunakan. varian dekat dari proyeksi Mercator, dan karena itu tidak dapat secara akurat menunjukkan daerah di sekitar kutub.

\section{G. Google Maps API}

Google Maps API adalah kumpulan API yang memungkinkan Kita menghamparkan data di Google Map yang disesuaikan. Kita dapat membuat aplikasi web dan seluler yang menarik dengan platform pemetaan canggih dari Google, termasuk data citra satelit, Street View, profil ketinggian, petunjuk arah mengemudi, peta bergaya, analisis, dan basis data tempat yang luas. Dengan cakupan global yang paling akurat di dunia dan komunitas pemetaan yang aktif dalam membuat pembaruan setiap harinya, pengguna akan mendapatkan manfaat dari layanan yang terus-menerus ditingkatkan.

H. Rapid Application Development (RAD)

Rapid Application Development (RAD) merupakan salah satu metode pengembangan suatu sistem informasi dengan waktu yang relatif singkat. Untuk pengembangan suatu sistem informasi yang normal membutuhkan waktu minimal 180 hari, akan tetapi dengan menggunakan metode RAD, suatu sistem dapat diselesaikan hanya dalam jangka waktu 30-90 hari. RAD adalah sebuah strategi pengembangan sistem dimana menekan kecepatan pengembangan melalui keterlibatan user ekstensif dalam kecepatan, iterative (berulang) dan incrumental construction dari serangkaian fungsi dari prototype sebuah sistem yang pada akhirnya akan mengalami perubahan secara bertahap menuju sistem akhir.

Pada saat RAD diimplementasikan, maka para pemakai bisa menjadi bagian dari keseluruhan proses pengembangan sistem dengan bertindak sebagai pengambil keputusan pada setiap tahapan pengembangan. RAD bisa menghasilkan suatu sistem dengan cepat karena sistem yang dikembangkan dapat memenuhi keinginan dari para pemakai sehingga dapat mengurangi waktu untuk pengembangan ulang setelah tahap implementasi.

Ide dasar dari RAD yaitu sebagai berikut:

1) Untuk lebih aktif lagi mempengaruhi users sistem dalam analisis, design, dan aktifitas kosntruksi

2) Untuk mengatur perkembangan sistem pada rangkaian yang terfokus, workshops yang intens yang secara bersamaan mempengaruhi sistem owners, users, analysts, designers, and builders

3) Untuk mempercepat requirements analysis dan design phase (fase desain) melalui pendekatan konstruksi iterative.

4) Untuk mengurangi jumlah waktu yang sebelumnya lebih banyak digunakan oleh user untuk mengerti cara kerja sistem.

\section{Unified Modeling Language (UML)}

UML merupakan singkatan dari "Unified Modeling Language" yaitu suatu metode permodelan secara visual untuk sarana perancangan sistem berorientasi objek, atau definisi UML yaitu sebagai suatu bahasa yang sudah menjadi standar pada visualisasi, perancangan dan juga pendokumentasian sistem software. Saat ini UML sudah menjadi bahasa standar dalam penulisan blue print software.

\section{J. Usecase diagram}

Use case diagram yaitu salah satu jenis diagram pada UML yang menggambarkan interaksi antara sistem dan aktor, use case diagram juga dapat men-deskripsikan tipe interaksi antara si pemakai sistem dengan sistemnya.

\section{K. Sequence diagram}

Sequence diagram menggambarkan interaksi antar objek di dalam dan disekitar sistem (termasuk pengguna, display, dan sebagainya) berupa message yang digambarkan terhadap waktu. 
L. Pengujian kotak hitam (Black Box Testing)

Pengujian kotak hitam berfokus pada persyaratan fungsional perangkat lunak. Artinya, teknik pengujian kotak hitam memungkinkan untuk membuat beberapa kumpulan kondisi masukan yang sepenuhnya akan melakukan semua kebutuhan fungsional untuk program. Pengujian kotak hitam berupaya untuk menemukan kesalahan dalam kategori berikut:

1) Fungsi yang salah atau hilang.

2) Kesalahan antarmuka.

3) Kesalahan dalam struktur data atau akses basis data eksternal.

4) Kesalahan perilaku atau kinerja.

5) Kesalahan inisialisasi dan penghentian.

\section{METODOLOGI PENELITIAN}

\section{A. Data Primer}

Sumber data primer diambil berdasarkan data sensus nasabah FIFGROUP tahun 2017.

\section{B. Data Sekunder}

Sumber data sekunder akan berasal dari studi literatur yang akan digunakan sebagai referensi dalam proses pengembangan aplikasi sistem informasi pemetaan lokasi nasabah FIFGROUP yang dijadikan objek penelitian ini.

\section{Tempat Dan Lokasi Penelitian}

Adapun penelitian ini dilakukan dalam rangka penyusunan tugas akhir yang akan dilaksanakan setelah proposal ini disetujui berdasarkan studi kasus pada FIFGROUP Kota Manado

\section{Alat dan Bahan}

Tools yang digunakan pada penelitian ini (lihat pada tabel I).

\section{E. Prosedur Penelitian}

Sistem informasi pemetaan berbasis android ini, menggunakan metode pengembangan sistem RAD (Rapid Application Development). Penelitian Aplikasi Pemetaan Lokasi Nasabah FIFGROUP Kota Manado dapat digambarkan dalam Work Breakdown Structure (WBS), yang mana di dalam WBS dirancang mengikuti tahapan RAD. Adapun tempat tahapan kerja yaitu analisis persyaratan, analisis modeling, desain modeling dan konstruksi (lihat pada gambar 1).

TABEL I. ALAT DAN BAHAN PENELITIAN

\begin{tabular}{|c|c|c|}
\hline NO & $\begin{array}{l}\text { Alat dan bahan } \\
\text { yang } \\
\text { digunakan }\end{array}$ & Keterangan \\
\hline 1. & Laptop & $\begin{array}{l}\text { Spesifikasi : } \\
-\quad \text { AsrockH87 Performance } \\
-\quad \text { Intel }{ }^{\circledR} \quad \text { Core } \\
\\
\text { 4670MCPU@3.40GHzR } \\
\text { AM 8 GB } \\
\text { - } \\
\text { OS Windows } 1064 \text { bit }\end{array}$ \\
\hline 2. & Software & $\begin{array}{ll}\text { - } & \text { Android studio } \\
\text { - } & \text { Android emulator } \\
\text { - } & \text { Java JDK }\end{array}$ \\
\hline
\end{tabular}

\section{APLIKASI PEMETAAN LOKASINASABAH FIFGROUP KOTA MANADO}

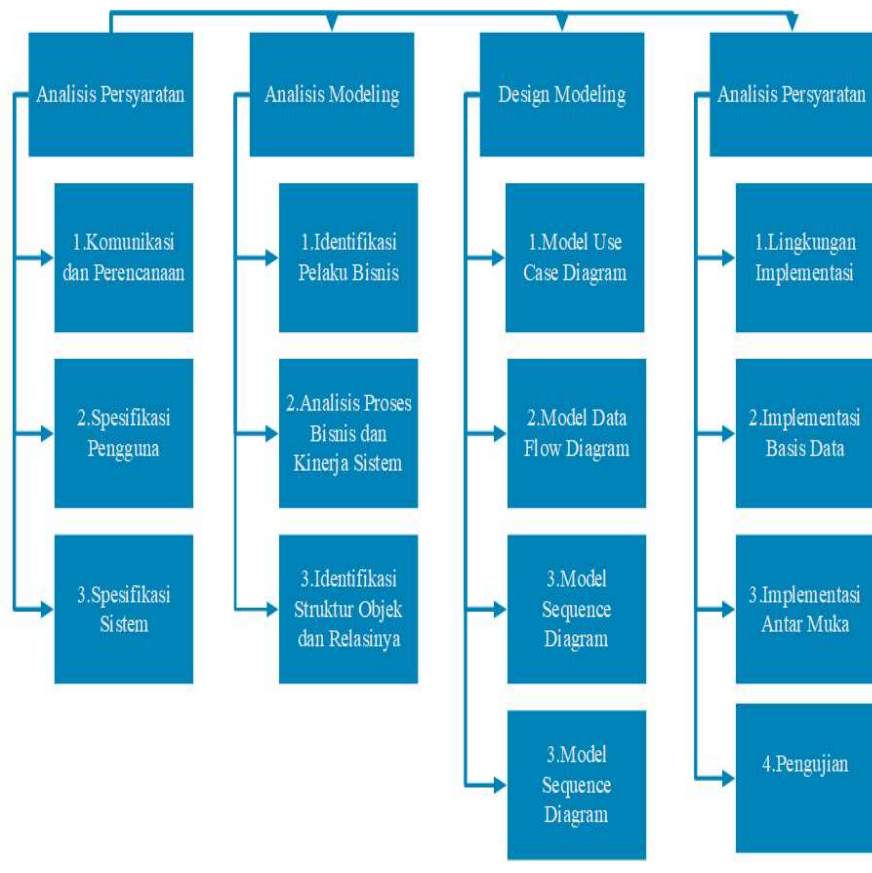

Gambar 1. Rencana Kerja Penelitian

\section{Analisis Persyaratan}

Fase analisis persyaratan ini menggunakan proses melakukan pengumpulan data dan mengidentifikasi layanan, batasan, dan obyektivitas dari pengumpulan data yang dilakukan. Hasil dari tahap ini berupa laporan penelitian dari pengembangan aplikasi, analisis spesifikasi awal, analisis persyaratan user dan sistem, dan informasi fitur pada aplikasi.

\section{Analisis Modeling}

Fase berikutnya adalah fase analisis modeling yang bertujuan menganalisis semua kegiatan dalam arsitektur sistem secara keseluruhan dengan cara identifikasi dan abstraksi sistem yang mendasar. menggambarkan perubahan keadaan suatu objek pada aplikasi kelas tertentu, memodelkan prilaku use case serta objek pada aplikasi dan menggambarkan perubahan suatu objek pada kelas tertentu. Hasil dari fase ini adalah basis data, antarmuka dan spesifikasi desain class diagram (lihat pada gambar 2).

\section{Desain Modeling}

Pada tahapan analisis dan desain modeling mengalami perulangan bertujuan untuk medapatkan hasil perancangan sistem yang benar-benar memenuhi kebutuhan. Hasil dari fase ini adalah Usecase diagram (lihat pada gambar 3)

\section{Desain Antarmuka}

Pada tahap selanjutnya adalah tahap merancang antarmuka untuk aplikasi yang akan dibangun, antarmuka ini bersifat sementara atau merupakan acuan, kedepannya saat pengimpelentasi antarmuka ini bisa saja terjadi perubahan sesuai kebutuhan. Antarmuka aplikasi dapat dilihat dari komponenkomponen penyusun antarmuka dan keterangan antarmuka yang ada ketika kondisi tertentu hasil dari fase desain antarmuka ini storyboard aplikasi . 
TABEL II. TAMPILAN STORYBOARD AWAL SISTEM

\begin{tabular}{lll}
\hline NO & TAMPILAN & KETERANGAN \\
& & \\
& & Tampilan ini akan \\
& muncul di awal \\
& user membuka \\
& aplikasi pemetaan \\
& lokasi nasabah \\
& FIFGROUP kota \\
& manado \\
\hline
\end{tabular}

TABEL III. TAMPILAN STORYBOARD MENU UTAMA

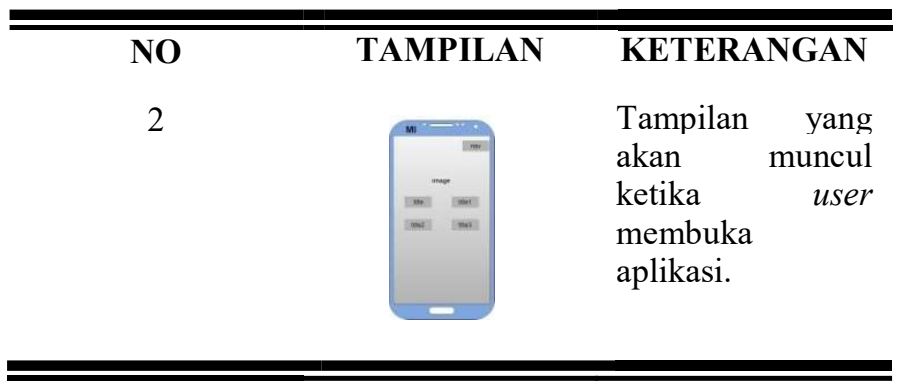

TABEL IV. TAMPILAN STORYBOARD INPUT DATA

\begin{tabular}{lll}
\hline NO & TAMPILAN & KETERANGAN \\
3. & Tampilan ini akan \\
& muncul ketika \\
& & ber membuka \\
& & bata \\
& & \\
\end{tabular}

TABEL V. TAMPILAN STORYBOARD MENU PENCARIAN

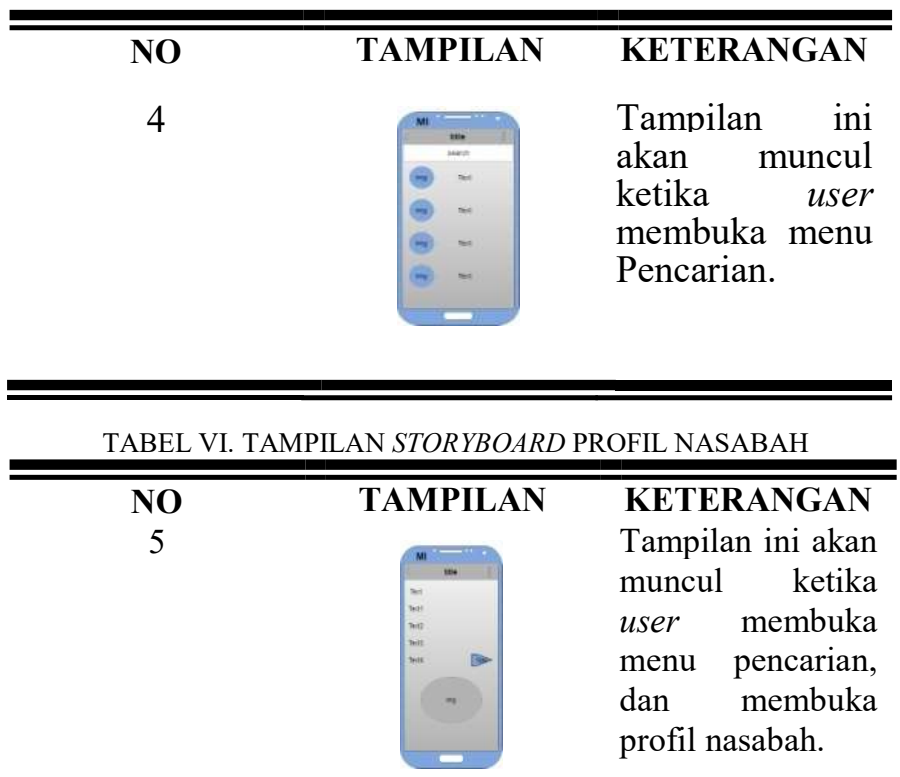

TABEL VII. TAMPILAN STORYBOARD PETA KOTA MANADO

\begin{tabular}{cll}
\hline NO & TAMPILAN & KETERANGAN \\
6 & Tampilan ini akan \\
& muncul ketika \\
& user membuka \\
& menu Peta Kota \\
& Manado. \\
& \\
&
\end{tabular}

TABEL VIII. TAMPILAN STORYBOARD FITUR ABOUT
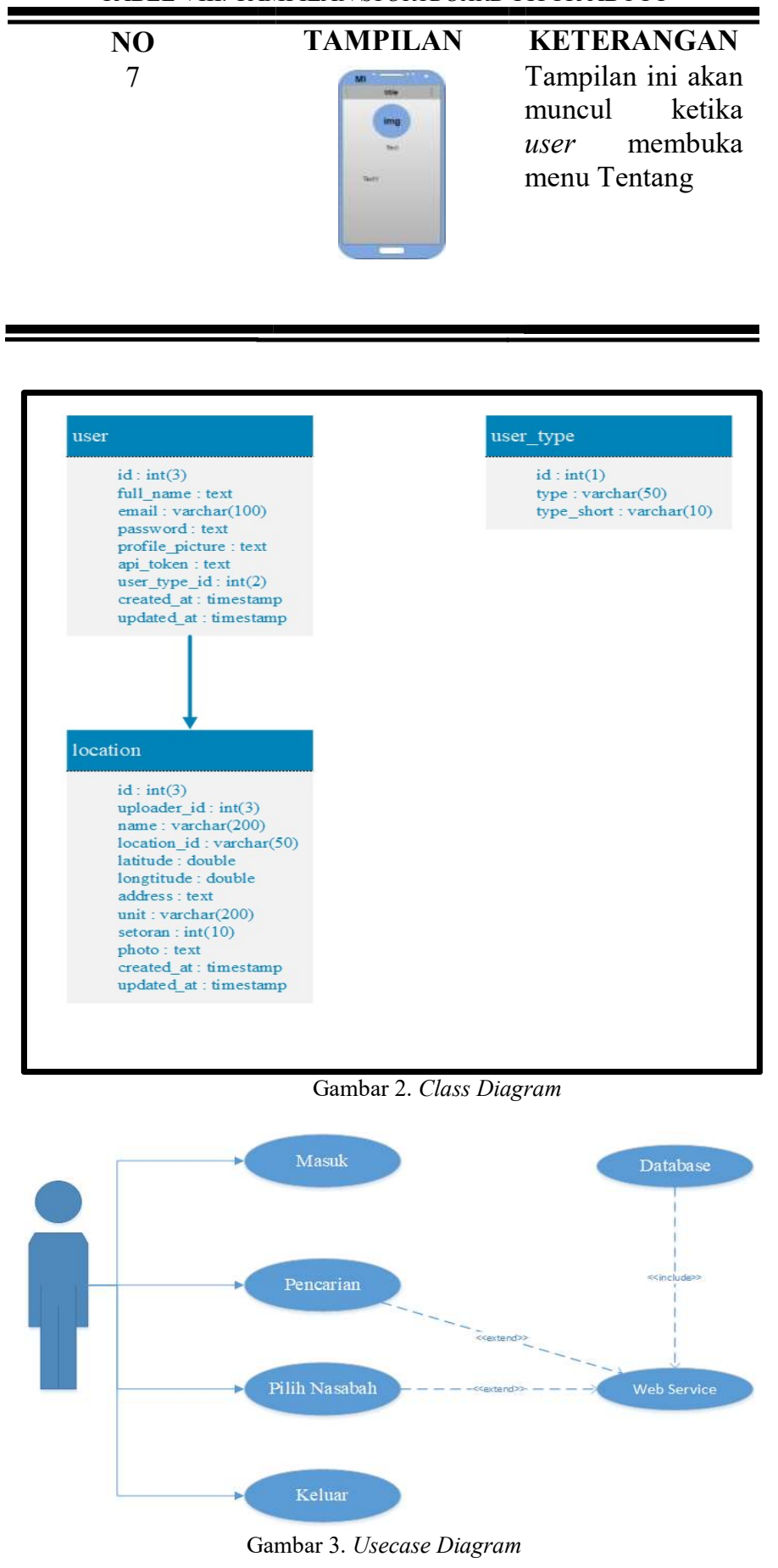


\section{HASIL DAN PEMBAHASAN}

A. Lingkungan Implementasi

Aplikasi pemetaan lokasi nasabah FIFGROUP kota manado berbasis android ini diimplementasikan pada smartphone berplatform android.

\section{B. Implementasi Basis Data}

Pembuatan aplikasi pemetaan lokasi nasabah FIFGROUP Kota Manado ini menggunakan database, dalam memanejemen database menggunakan phpMyAdmin (lihat pada gambar 4).

\section{Implementasi Antarmuka}

Implementasi antarmuka dan penjelasan tiap tampilan Aplikasi pemetaan lokasi nasabah FIFGROUP Kota Manado (lihat pada gambar 5 sampai dengan gambar 11).

Implementasi antarmuka dan penjelasan tiap tampilan Aplikasi pemetaan lokasi nasabah FIFGROUP Kota Manado (lihat pada gambar 5 sampai dengan gambar 11).
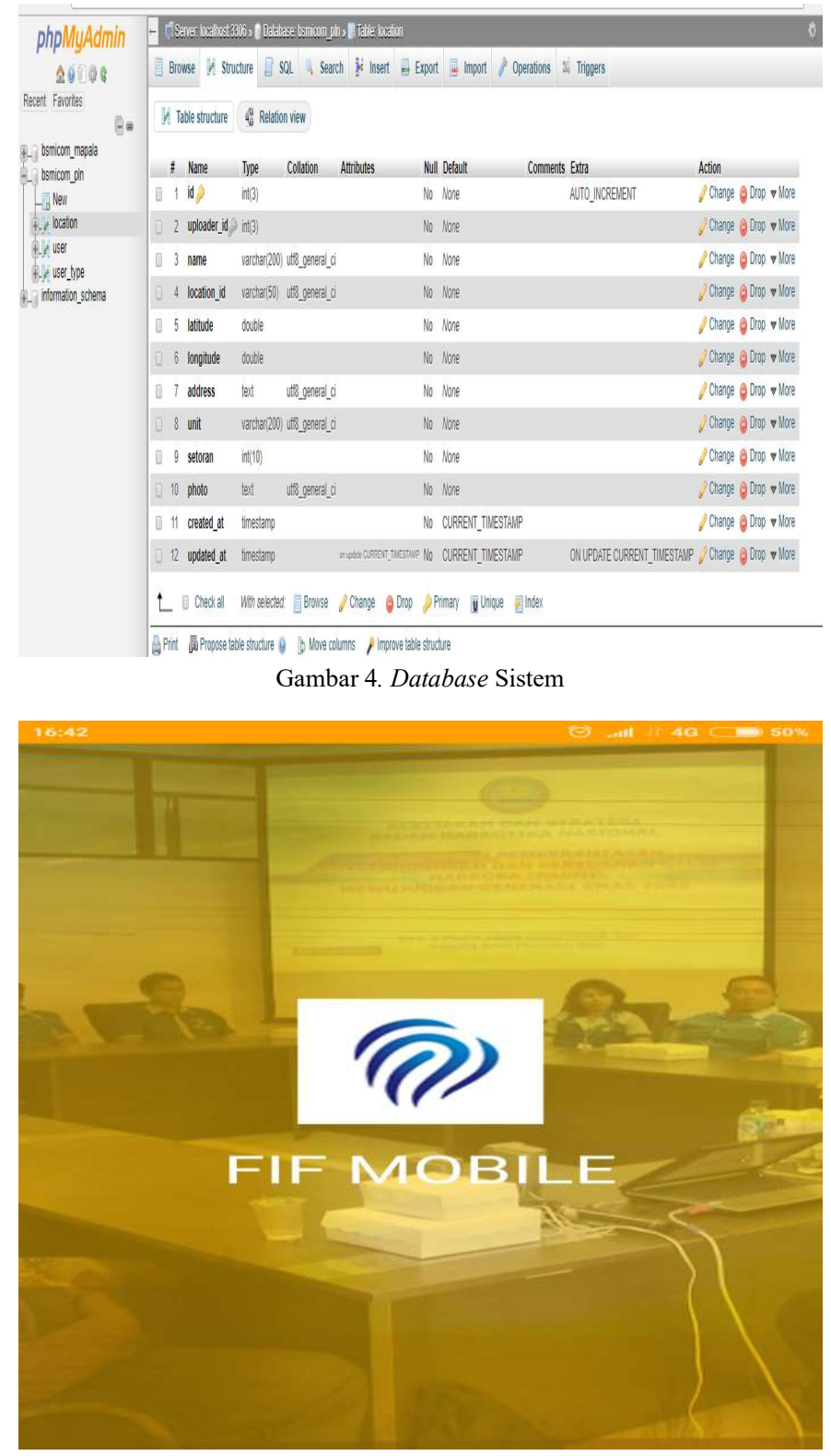

Gambar 5. Tampilan Awal Sitem
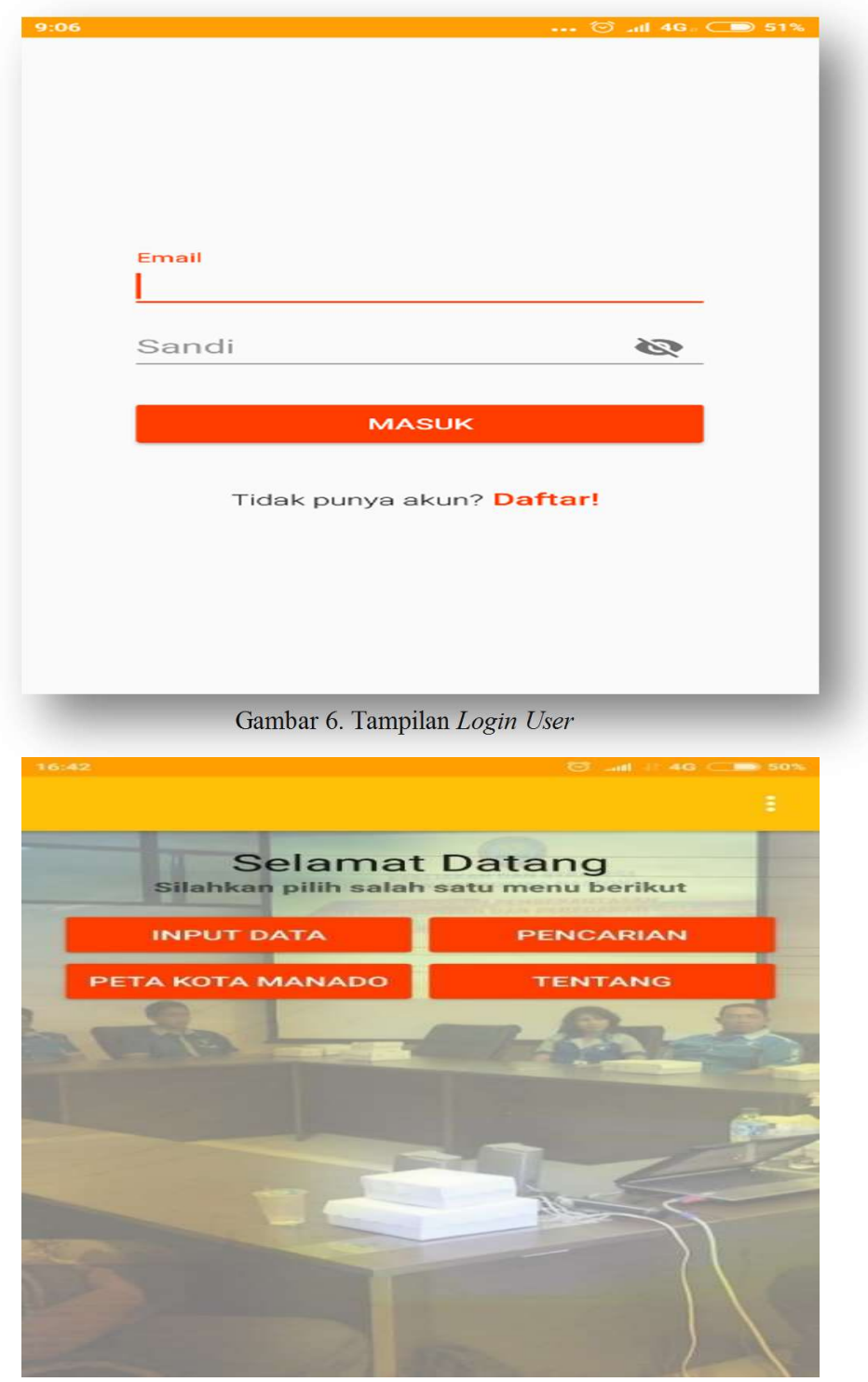

Gambar 7. Tampilan Menu

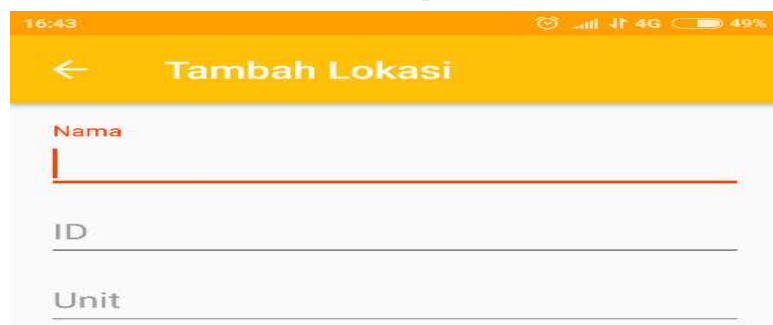

Alamat

Latitude

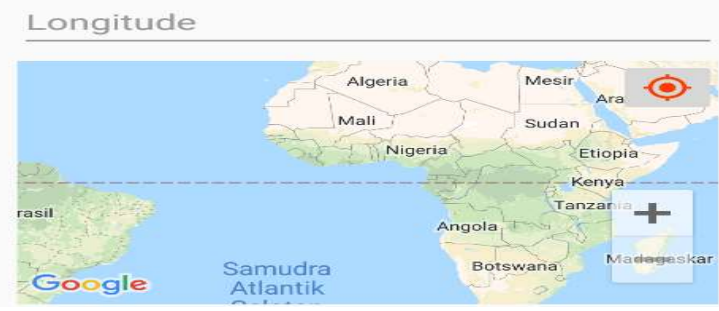

Gambar 8. Tampilan Menu Input Data 

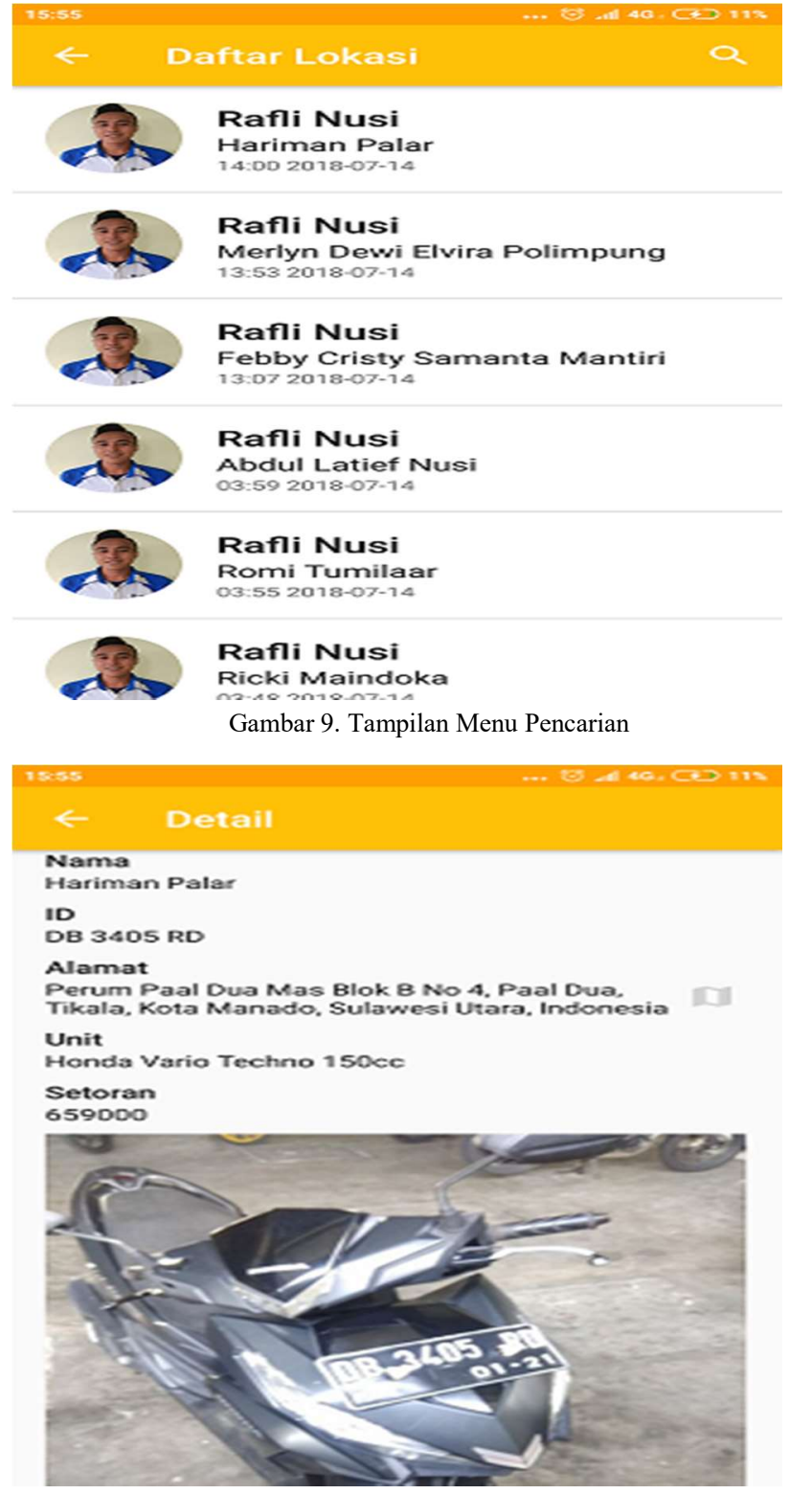

Gambar 10. Tampilan Data Nasabah

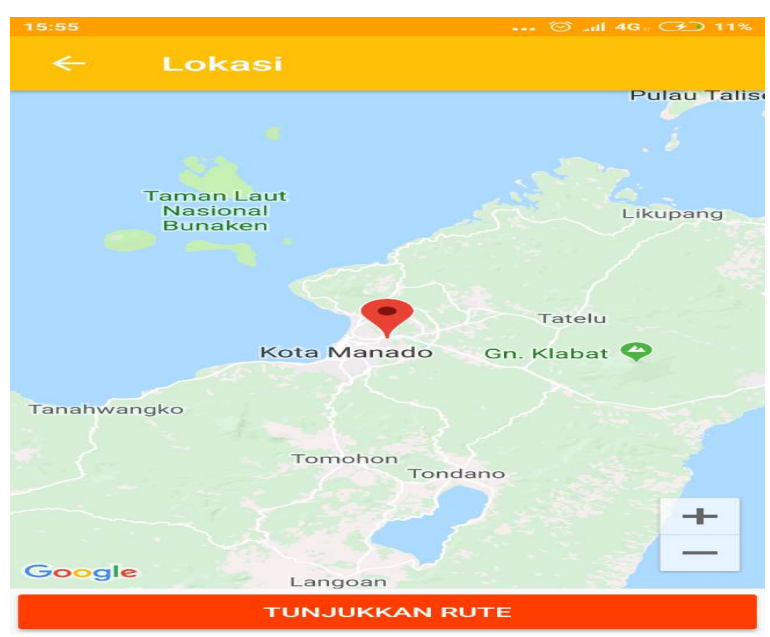

Gambar 11. Tampilan Lokasi Nasabah
Tampilan Awal Sitem

Tampilan awal yang muncul sementara sebelum ke tampilan utama atau menu utama. Saat aplikasi android dibuka maka user akan masuk pada tampilan splashscreen seperti pada gambar 5 . Tampilan ini menampilkan logo dan nama dari aplikasi. Saat aplikasi dibuka, splashscreen memakan waktu 2 sampai 4 detik setelah itu aplikasi terbuka.

\section{Tampilan Login User}

Tampilan untuk user dapat dilihat pada gambar 6, yang akan login kedalam aplikasi, User diminta untuk mengisi email dan sandi agar bisa masuk ke dalam aplikasi. Bila user belum mempunyai email, user bisa daftar terlebih dahulu agar bisa masuk ke dalam aplikasi.

\section{Tampilan Menu}

Setelah user membuka aplikasi, akan muncul tampilan awal untuk memilih langkah apa selanjutnya yang akan dilakukan user, user bisa memilih melakukan input data, pencarian data, melihat peta kota dan pilihan tentang aplikasi, yang dapat dilihat pada gambar 7 .

\section{Menu Input Data}

Setelah user memilih untuk melakukan input data konsumen, user akan masuk ke menu input data, pada tahap ini, user bisa memasukan nama, id, unit, alamat, latitude, dan longtitude sesuai data yang benar untuk kemudahan pada saat nanti akan melakukan penagihan ataupun survei. Yang dpat dilihat pada gambar 8 .

\section{Tampilan Menu Pencarian}

Setelah selesai menginput data, user bisa melihat data yang sudah di masukan pada menu pencarian, menu ini juga berguna untuk mencari dan melihat data nasabah. Data nasabah yang sudah dimasukkan ke database akan muncul di aplikasi. Tampilan menu pencarian dapat dilihat pada gambar 9 .

\section{Tampilan Data Nasabah}

User dalam hal ini adalah kolektor, juga bisa meihat detail data nasabah yaitu nama, id, alamat, unit, dan setoran pada halaman data nasabah untuk mempermudah Kolektor dalam melakukan pekerjaan dalam hal ini penagihan cicilan, yang dapat dilihat pada gambar 10 .

\section{Lokasi Nasabah}

Ketika user memilih salah satu data nasabah akan muncul icon navigation google di sebelah alamat, setelah di klik maka akan muncul popup lokasi nasabah. Selain itu, dibawah akan muncul tunjukkan rute, agar user mengetahui jalur menuju lokasi tersebut. Tampilan untuk lokasi nasabah dapat dilihat pada gambar 11.

\section{A. Kesimpulan}

\section{IV.PENUTUP}

Dengan adanya pengujian pada tahap akhir didapatkan kesimpulan sebagai berikut :

1) Aplikasi ini dibuat untuk mempermudah kolektor melakukan proses penagihan kepada nasabah FIFGROUP. 
2) Dalam proses pembuatannya, aplikasi ini menggunakan bahasa pemrograman Java dan PHP. Untuk tools pembuatan menggunakan Android Studio, Sublime Text dan Ms.Visio.

3) Aplikasi mobile berbasis android ini menggunakan metodologi Rapid Application Development (RAD)dan aplikasi ini juga dapat berjalan dengan baik pada semua perangkat Android.

\section{B. Saran}

Aplikasi pemetaan lokasi nasabah FIFGROUP ini dibuat untuk mempermudah para kolektor agar lebih cepat dan mudah mendapatkan informasi dari nasabah. Saran untuk pengembangan platform selanjutnya agar aplikasi dapat dibuat lebih baik lagi, dengan menambah fitur- fitur yang masih kurang diantaranya pembuatan report nasabah yang sudah ditagih atau belum tiap bulannya. Juga dibuat lebih luas seperti aplikasi dapat berjalan di iOS, mobile, windows phone bahkan lainnya

\section{KUTIPAN}

[1] Abdul Kosasi.S. dan Yuliani. A.E. 2015. Penerapan RAD Pada Sistem Informasi Penjualan Sepeda Online. SIMETRIS, Vol, 6 No, 1 pp, 27-28.

[2] Haviluddin. 2011. Memahami Penggunaan UML (Unified Modelling Language). Jurnal Informatika Mulawarman, Vol.6 No 1.

[3] Jardine Cycle, Carriage.Jardine Cycle \& Carriage.https://id.wikipedia.org/wiki/Astra_International Diakses tanggal 2018-08-23.Astra International.

[4] Nazruddin. Safaat. H. 2012, (Edisi Revisi). Pemograman Aplikasi MobileSmartphone dan Tablet PC Berbasis Android. Informatika. Bandung

[5] Noertjahyana, A. 2002. Studi Analisis Rapid Application Development Sebagai Salah Satu Alternatif Metode Pengembangan Perangkat Lunak. Jurnal Informatika, Vol. 3, No. 2.

[6] Prahasta. Eddy. 2014,Sistem Informasi Geografis tool dan plug-in Informatika, Bandung

[7] Pressman. R.S. 2010. Rekayasa Perangkat Lunak buku 1, edisi 7, terjemahan Tim Penerjemah Andi. Yogyakarta

[8] Program Studi Kajian Pengembangan Perkotaan, Program Pasca Sarjana Universitas Indonesia, Jakarta 10430, Indonesia

[9] Sutraman. 2003. Membangun Aplikasi Web dengan PHP dan MySQL. Graha Ilmu, Yogyakarta.

[10] Whitten, Jeffery, L., Bentley, Lonnie, D., Dittman, and Kevin, C., 2004, Metode Desain dan Analisis Sistem (diterjemahkan oleh Tim Penerjemah ANDI), Edisi 5, Penerbit ANDI. Yogyakarta.
Sekilas dari penulis dengan nama lengkap Erlandy Aristianto ,lahir di kota Manado, Provinsi Sulawesi Utara. Anak Pertama dari tiga bersaudara. Dengan pendidikan Sekolah Dasar SD Negeri 2 Manado. Kemudian Melanjutkan ke Sekolah Menengah Pertama Negeri SMP Negeri 1 Sentani. Kemudian melanjutkan ke Sekolah Menengah Atas SMA N 1 Manado.

Setelah lulus tahun 2011 melanjutkan ke Perguruan Tinggi di Universitas Sam Ratulangi Manado dengan mengambil Jurusan Teknik Informatika. Pada tahun 2018 bulan Januari, penulis membuat Skripsi demi memenuhi syarat Sarjana(S1 )dengan penelitian berjudul Aplikasi Pemetaan Berbasis Android oleh duadosen pembimbing yaitu Arie S.M.Lumenta, ST., MT Dan Yaulie Deo.Y.Rindengan S.MM. MSc. sehingga pada tanggal 20 September 2018 penulis resmi lulus di Teknik Informatika Universitas Sam Ratulangi Manado dan menyandang gelar Sarjana Komputer dengan predikat Sangat memuaskan. 